\title{
Risk and Confidence Analysis for Fuzzy Multicriteria Decision Making
}

\author{
Wei Wang and Norman Fenton \\ Risk Analysis and Decision Research Group \\ Dept Computer Science \\ Queen Mary University of London \\ Mile End Road, London E1 4NS \\ weiwang@dcs.qmul.ac.uk, norman@dcs.qmul.ac.uk
}

Tel: 442078827860

Fax: 442089806533

\begin{abstract}
Recent research has recognised that multicriteria decision making (MCDM) should take account of uncertainty, risk and confidence. This paper takes this research forward by using linguistic variables and triangular fuzzy numbers to model the decision maker's (DM) risk and confidence attitudes in order to define a more complete MCDM solution. To illustrate the computation process and demonstrate the feasibility of the results we use a travel problem that has been used previously to assess MCDM techniques. The results show that the method is useful for tackling imprecision and subjectivity in complex, ill-defined and human-oriented decision problems.
\end{abstract}

Keywords - multicriteria decision making, triangular fuzzy numbers, linguistic variables 


\section{Introduction}

Multicriteria decision making (MCDM) refers to screening, prioritising, ranking, or selecting a set of alternatives (also referred to as "candidates" or "actions") under usually independent, incommensurate or conflicting criteria $[2,16,28]$. We will use the following example (also used in $[15,31])$ to illustrate the concepts and methods throughout:

Example: We have to reach the airport from our home to catch an airplane. The MCDM problem here is to select an appropriate travel type from three alternatives: Car, Taxi and Train. Our criteria are price, journey time, and comfort.

An MCDM problem is characterized by a) the ratings of each alternative with respect to each criteria and b) the weights given to each criteria. Classical MCDM methods assume that the ratings of alternatives and the weights of criteria are crisp numbers. Increasingly, this is recognized as unrealistic. In the above example, the decision maker (DM) will be unable to assign a crisp number for the journey time of a car since this value is influenced by many factors. Generally, uncertainties arise from: unquantifiable information, incomplete information, unnobtainable information, and partial ignorance [8].

Since classical MCDM methods cannot handle problems with such imprecise information, the representation and interpretation of "uncertainty" and human-related subjective preference is needed [40]. The use of probabilistic methods for this purpose in MCDM has been explored in $[15,31]$, but fuzzy set theory [38] seems to have been the most commonly used method. The general use of fuzzy set theory in MCDM is explored in [3, 24, 25, 37], while specific fuzzy MCDM methods can be found in [4, 6, 8-12, 14, 27, 32-34]. Fuzzy decision making with partial preference information has been explored in [5, 18, 25, 30]. In [35-37], Yager included fuzzy 
methods, probabilistic information as well as the DM's attitudes and preferences for decisionmaking under uncertainty.

In this paper, we first introduce the general fuzzy MCDM approach (Section 2). Then we focus on the two dimensions where we believe the DM's attitude is most subjective: risk (Section 3) and confidence (Section 4). We handle risk by extending the so-called linguistic approach $[1,13,17$, $21,39]$ that has previously been explored with fuzzy MCDM in [7, 10-12, 20, 32-34]. The linguistic approach is an approximate way to represent natural words or sentences used in human judgment and perception. Linguistic decision analysis $[4,17,18,26]$ transforms the linguistic description of the DM into a mathematical model to provide a flexible framework for solving decision problems. To handle confidence we use the fuzzy $\alpha$ cut concept [19] in addition to a linguistic approach. Our method for ranking the performance of alternatives is based on the kind of two-phase approach adopted in $[8,25,40]$. The first phase is to aggregate performance of the ratings of the alternatives under the criteria. The second phase is to rank alternatives with respect to aggregated performances.

\section{General Fuzzy MCDM Approach}

First we describe the general approach to fuzzy MCDM without considering risk attitudes and confidence.

\subsection{Problem formulation and definitions}

A general multicriteria decision problem with $m$ alternatives $A_{i}(i=1, \ldots, m)$ and $n$ criteria $C_{j}$ $(j=1, \ldots, n)$ can be concisely expressed as:

$D=\left[x_{i j}\right]$ and $W=\left(w_{j}\right)$, where $i=1, . ., m$ and $j=1, . ., n$. 
Here $D$ is referred to as the decision matrix (where the entry $x_{i j}$ represents the rating of alternative $A_{i}$ with respect to criterion $C_{j}$ ), and $W$ as the weight vector (where $w_{j}$ represents the weight of criterion $C_{j}$ ). In general we classify criteria as either:

- benefit criteria (where the higher the value of $x_{i j}$ the better it is for the DM) or

- cost criteria (where the lower the value of $x_{i j}$ the better it is for the DM).

Because we wish to consider fuzzy, as opposed to crisp, values in $D$ and $W$ we shall use the notation:

$\tilde{D}=\left[\tilde{x}_{i j}\right]$ and $\tilde{W}=\left(\tilde{w}_{j}\right)$

whereby $\tilde{x}_{i j}$ represents the fuzzy rating of alternative $A_{i}$ with respect to criterion $C_{j}$, and $\tilde{w}_{j}$ represents the fuzzy weight of criterion $C_{j}$. In particular, an intuitively easy and effective approach to capturing the expert's uncertainty about the value of an unknown number is a triangular fuzzy number:

Definition: A triangular fuzzy number $\tilde{a}$ is defined by a triplet $\left(a_{1}, a_{2}, a_{3}\right)$. The membership function is defined as [19]:

$$
\mu_{\tilde{a}}(x)= \begin{cases}\left(x-a_{1}\right) /\left(a_{2}-a_{1}\right), & a_{1} \leq x \leq a_{2}, \\ \left(a_{3}-x\right) /\left(a_{3}-a_{2}\right), & a_{2} \leq x \leq a_{3}, \\ 0, & \text { otherwise. }\end{cases}
$$

The triangular fuzzy number is based on a three-value judgment: the minimum possible value $a_{1}$, the most possible value $a_{2}$ and the maximum possible value $a_{3}$. 
Example: Table 1 shows the decision matrix and weight vector for the travel problem introduced in Section 1. In this example the criteria price and journey time are cost criteria measured in pounds and minutes respectively. The criterion comfort is a value criterion measured on a scale from 1 to 10 . The ratings in the decision matrix are expressed as triangular fuzzy numbers (so, for example, the car journey to the airport most typically costs 10 pounds but it can be as low as 9 and as high as 12). For simplicity the weights are crisp numbers summing to 1 (usually the DM is able to express the weights in this way).

\section{Table 1 Decision matrix and weight vector}

\subsection{Normalization}

To deal with criteria on different scales, we apply a normalization process. Specifically, we normalize the fuzzy numbers in the decision matrix as the performance matrix:

$\tilde{P}=\left[\tilde{p}_{i j}\right]$,

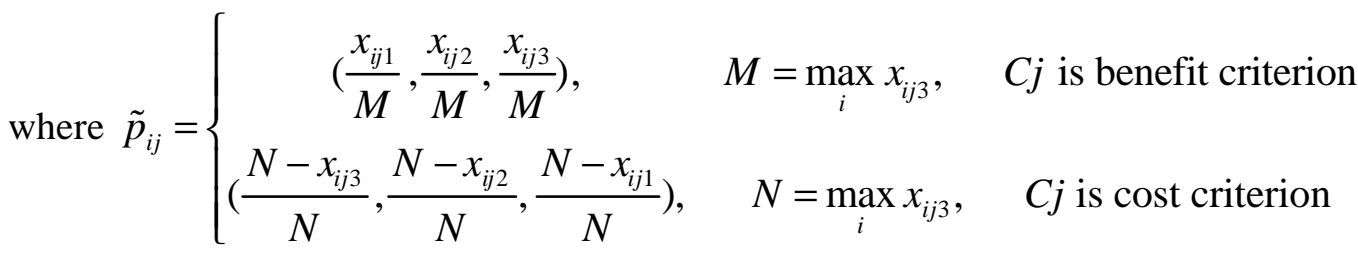

This method preserves the ranges of normalized triangular fuzzy numbers to $[0,1]$.

Example: The performance matrix is calc ulated by (4) and shown in Table 2.

Table 2 Performance matrix

\subsection{Weighting the criteria}

We construct the weighted performance matrix by multiplying the weight vector by the decision matrix as: 
$\tilde{P}^{w}=\left[\tilde{p}_{i j}^{w}\right]$,

where $p_{i j 1}^{w}=w_{j 1} p_{i j 1}, p_{i j 2}^{w}=w_{j 2} p_{i j 2}, p_{i j 3}^{w}=w_{j 3} p_{i j 3}, i=1,2, \ldots, m$, and $j=1,2, \ldots, n$.

Example: The running example is shown in Table 3.

Table 3 Weighted performance matrix

\subsection{Performance of alternatives}

We use the vertex method [7] to calculate alternatives' performance index with reference to ideal solutions [16]. The most preferred alternative should have the shortest distance from the positive ideal solution and the longest distance from the negative ideal solution.

Definition: Let $\tilde{a}=\left(a_{1}, a_{2}, a_{3}\right)$ and $\tilde{b}=\left(\begin{array}{lll}b & b_{2}, & b_{3}\end{array}\right)$ be two positive triangular fuzzy numbers, then the vertex method defines the distance between them as:

$d(\tilde{a}, \tilde{b})=\left\{\left[\left(a_{1}-b_{1}\right)^{2}+\left(a_{2}-b_{2}\right)^{2}+\left(a_{3}-b_{3}\right)^{2}\right] / 3\right\}^{1 / 2}$

For the normalized fuzzy performance matrix, we define the positive ideal solution

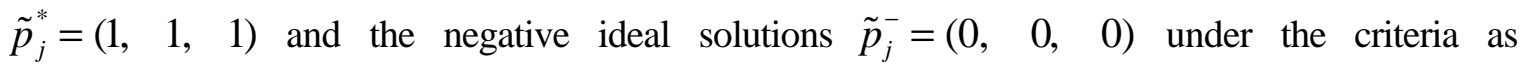
references to measure alternatives' performance [7]. By the vertex method, the distance between each alternative and the positive ideal solution and the negative ideal solution is calculated as:

$d_{i}^{*}=\sum_{j=1}^{n} d\left(\tilde{p}_{i j}^{w}, \tilde{p}_{j}^{*}\right)$
$d_{i}^{-}=\sum_{j=1}^{n} d\left(\tilde{p}_{i j}^{w}, \tilde{p}_{j}^{-}\right)$

where $i=1, . ., m$ and $j=1, \ldots n$.

We calculate performance index for each alternative as: 
$p_{i}=d_{i}^{-}+n-d_{i}^{*} / 2 n$

where $i=1, . ., m$, and $n$ is the number of criteria. The nearer $p_{i}$ gets to 1 the better alternative's performance.

Example: The alternative's distance to the positive ideal solution and negative ideal solutions is calculated by (7) and (8). The alternatives' performance index is calculated by (9) and shown in Table 4 together with ranking orders.

Table 4 Performance index

\section{Fuzzy MCDM by incorporating risk attitudes}

The general approach can provide a basic ranking of the alternatives, but it cannot deal with the DM's attitudes towards risk and uncertainty. In this section we explain how to incorporate the DM's risk attitudes into the general fuzzy MCDM approach. The linguistic approach to modeling risk attitudes in fuzzy MCDM [32-34] uses the notion of "optimism" and "pessimism". The key issue for us is to be able to use natural language to describe an appropriate range of attitudes between the extremes of "optimism" and "pessimism". The number of terms needs to be small enough so as not to impose pointless precision, yet rich enough to allow proper discrimination of the assessments [17]. Based on Miller's theory of cognitive retention [23] we use nine as the maximum number of terms for the DM's assessments. 


\subsection{Modeling risk attitudes}

For benefit criteria, the DM expects a maximum value as the best value. For cost criteria, the DM expects a minimum value as the best value. To incorporate the DM's risk attitude to the triangular fuzzy number $\left(a_{1}, a_{2}, a_{3}\right)$, we regard $\left(a_{1}, a_{2}, a_{3}\right)$ as the neutral attitudes, $\left(a_{1}, a_{3}, a_{3}\right)$ and $\left(a_{1}, a_{1}, a_{3}\right)$ as absolutely optimistic (AO) (absolutely pessimistic (AP)) and absolutely pessimistic (AP) (absolutely optimistic (AO)) for benefit (cost) criteria. In general we use an ordered structure to incorporate other risk attitudes in $\left(a_{1}, a_{2}, a_{3}\right)$ according to benefit (cost) criteria as shown in Table 5. The first column of Table 5 shows the set of linguistic terms. The case of benefit criteria in the second column and cost criteria in the third column shows the associated triangular fuzzy numbers derived from the triangular fuzzy number $\left(a_{1}, a_{2}, a_{3}\right)$. The approach described here is easily generalized for the case where there are $n$ as opposed to 9 linguistic terms.

\section{Table 5 Linguistic terms of risk attitudes}

\subsection{Performance of alternatives on risk attitudes}

Now that we have a triangular fuzzy numbers that capture the DM's risk attitude we incorporate these into the decision matrix as:

$\tilde{D}^{r}=\left[\tilde{x}_{i j}^{r}\right]$,

where $\tilde{x}_{i j}^{r}$ is the triangular fuzzy number derived from $\tilde{x}_{i j}$ under the specific risk attitude by Table 5. After normalization and weighting of criteria, we obtain the performance index with respect to risk attitudes.

Example: The alternatives' performance index and ranking orders under different risk attitudes is shown in Table 6. 
Table 6 Performance index with respect to risk attitudes

\section{Fuzzy MCDM by incorporating confidence attitudes}

Table 6 is interesting in that it seems to suggest that any DM ranging from an extreme optimist to an extreme pessimist will always choose the Car as the preferred alternative (although the order of train and taxi vary). However, this result does not take account of the DM's confidence/uncertainty about the value of a rating. For example, the fuzzy value of journey time for car is $(70,100,120)$ compared with $(70,80,90)$ for train. Somebody who was extremely confident about the values would tend to believe that the most likely value was the true value in each case, i.e. 100 and 80 respectively. Thus, a pessimist (from the risk perspective) who was nevertheless extremely confident about the value would be more likely to favour the train than the car. In this section we formalize these notions so that we are able to complete our MCDM process by incorporating the DM's confidence on top of their risk attitudes. We draw on work from $[14,32]$ (including the notion of the $\alpha$ cut concept) and [29].

\subsection{Incorporating confidence levels}

To assess confidence and uncertainty about a triangular fuzzy number we use the $\alpha$ cut concept as described in Figure 1.

Figure 1 A triangular fuzzy number $\tilde{A}$ and its $\alpha$-cut triangular fuzzy number

The idea is that $\alpha \in[0,1]$ is a basic measure of our confidence about the fuzzy number. We use it to compute a refined fuzzy number that is 'closer' to the value with highest possibility as $\alpha$ tends to 1 . Formally, assuming that the confidence in the triangular fuzzy number $\tilde{a}=\left(\begin{array}{lll}a_{1}, & a_{2}, a_{3}\end{array}\right)$ is at level $\alpha$, the refined fuzzy number is defined as: 
$\tilde{a}^{\alpha}=\left(a_{1}(\alpha), a_{2}, a_{3}(\alpha)\right)=\left(a_{1}+\alpha\left(a_{2}-a_{1}\right), a_{2}, a_{3}-\alpha\left(a_{3}-a_{2}\right)\right)$.

Having already incorporated the risk attitude in the decision matrix as in Section 3, we can now construct the decision matrix with risk attitude given confidence le vel $\alpha$ as:

$\tilde{D}^{\alpha}=\left[\tilde{x}_{i j}^{\alpha}\right]$

where $\tilde{x}_{i j}^{\alpha}$ is the triangular fuzzy number derived from $\tilde{x}_{i j}^{r}$ under the specific confidence level by (13). Suppose that there are $l$ confidence levels. After normalization and weighting of criteria, we obtain the performance index vector given confidence levels as:

$P_{i}=\left(p_{i k}^{\alpha}\right), \quad$ where $\alpha=k-1 / l-1, \quad(l \geq 2), i=1, \ldots, m$, and $k=1, \ldots, l$.

Example: By applying the above equations we get the performance index under neutral risk attitude with 11 confidence levels shown in Table 7.

Table 7 Performance index under neutral risk attitude with 11 confidence levels

\subsection{Modeling of confidence attitudes}

Instead of providing a direct value $\alpha$ to construct a confidence level, we next use a linguistic variable to represent the DM's qualitative assessment of confidence. As before we use a nine-point linguistic scale shown in Table 8. Intuitively the membership value of confidence increases linearly as $\alpha$ increase from 0 to 1 .

Table 8 Linguistic terms of confidence attitude

\subsection{Performance of alternatives on confidence attitudes}

In general, assuming a total of $l(l \geq 2)$ confidence levels, we define the normalized confidence membership vector as: 
$C_{L T}=\left(c_{k} / \sum_{k=1}^{l} c_{k}\right)$

where $c_{k}=\mu_{L T}(\alpha), \alpha=k-1 / l-1, k=1, \ldots, l$ and $L T$ represents linguistic terms $A C, V C, C$, $F C, N, F N C, N C, V N C$, and $A N C$, respectively. Based on the confidence membership vectors (16), the performance of the $i$ th alternative under confidence attitudes is:

$p_{i}^{L T}=P_{i}\left(C_{L T}\right)^{T}=\sum_{k=1}^{l} p_{i k} c_{k} / \sum_{k=1}^{l} c_{k}$.

The DM can rank, prioritize, and select alternatives under different risk attitudes and confidence attitudes according to the performance index.

Example: The alternatives' performance index and ranking orders under neutral risk attitude with respect to different confident attitudes are shown in Table 9.

Table 9 Performance index under neutral risk attitude with respect to confidence attitudes

For clear evaluation and analysis, we calculate and show the alternatives' performance index under risk and confidence attitude simultaneously. Performance index and ranking orders of Car under different risk and confidence attitudes are shown in Table 10 and Table 11, respectively. Those of Taxi are shown in Table 12 and Table 13, respectively, and those of Train are shown in Table 14 and Table 15 , respectively.

Table 10 Performance index of $\mathrm{Car}$ under risk and confidence attitudes

Table 11 Ranking order of Car under risk and confidence attitudes

Table 12 Performance index of Taxi under risk and confidence attitudes

Table 13 Ranking order of Taxi under risk and confidence attitudes

Table 14 Performance index of Train under risk and confidence attitudes

Table 15 Ranking order of Train under risk and confidence attitudes 
Thus, the DM can choose the best alternative under different risk and confidence attitudes accordingly. For example, a DM who is absolutely pessimistic (with respect to risk attitude) but very confident will rank Car as the last alternative and Taxi as the first, whereas the DM who is absolutely pessimistic and fairly confident will rank Train as first.

\section{Conclusions}

Since multicriteria decision problems generally involve uncertainty it is important to incorporate different types of uncertainty in any proposed solution. We have presented a novel fuzzy MCDM approach based on risk and confidence analysis, that we believe is effective in tackling complex, ill-defined and human-oriented decision problems. In summary our approach consists of the following steps:

1. Formulate the problem in terms of the (fuzzy) decision matrix and the weight vector.

2. Normalize the decision matrix as the performance matrix.

3. Construct the weighted performance matrix.

4. With reference to ideal solutions, calculate alternatives' performance index.

5. According to the DM's risk attitudes (which can be characterized linguistically), construct the performance matrix with risk attitudes. Calculate alternatives' performance index by 2, 3 and 4 under risk attitudes.

6. Construct the performance matrix with risk attitudes on confidence levels and calculate performance index vector with respect to confidence levels by 2,3 , and 4 .

7. According to the DM's confidence attitudes (which can again be characterized linguistically), determine the confidence membership vectors and calculate alternatives' performance index under confidence attitudes. 


\section{References}

[1] B. Arfi, Fuzzy decision making in politics: a linguistic fuzzy-set approach (LFSA), Political Analysis 13 (2005) 23-56.

[2] V. Belton, T.J. Steward, Multiple Criteria Decision Analysis-An Integrated Approach, Kluwer Academic Publishers, Boston/Dordrecht/London, 2002.

[3] R.E. Bellman, L.A. Zadeh, Decision-making in a fuzzy environment, Management Science 17 (1970) 141-164.

[4] P.P. Bonissone, A fuzzy sets based linguistic approach: theory and application, in: M.M. Gupta, E. Sanchez (Eds.), Approximate Reading in Decision Analysis, Amsterdam, NorthHolland, 1982, pp. 329-339.

[5] C. Carlsson, Tacking an MCDM-problem with the help of some results from fuzzy set theory, European Journal of Operational Research 10 (1982) 270-281.

[6] E. Carrizosa, E. Conde, F.R. Fernandez, J. Puerto, Multicriteria analysis with partial information about the weighting coefficients, European Journal of Operational Research 81 (1995) 291-301.

[7] C.T. Chen, Extensions of the TOPSIS for group decision-making under fuzzy environment, Fuzzy Sets and Systems 114 (2000) 1-9.

[8] S.J. Chen and C.L. Hwang, Fuzzy Multiple Attribute Decision Making Methods and Applications, Springer-Verlag, Berlin Heidelberg, 1992.

[9] S.M. Chen, A new method for tool steel materials selection under fuzzy environment, Fuzzy Sets and Systems 92 (1997) 265-274.

[10] C.H. Cheng, K.L. Yang, C.L. Hwang, Evaluating attack helicopters by AHP based on linguistic variable weight, European Journal of Operational Research 116 (1999) 423-435.

[11] C.H. Cheng, Evaluating weapon systems using ranking fuzzy numbers, Fuzzy Sets and Systems 107 (1999) 25-35.

[12] C.H. Cheng, Y. Lin, Evaluating the best main battle tank using fuzzy decision theory with linguistic criteria evaluation, European Journal of Operational Research 142 (2002) 174-186.

[13] M. Delgado, J.L. Verdegay, M.A. Vila, Linguistic decision making models, International Journal of Intelligent Systems 7 (1992) 479-492.

[14] H. Deng, Multicriteria analysis with fuzzy pairwise comparison, International Journal of Approximate Reasoning 21 (1999) 215-231.

[15] N. Fenton, M. Neil, Making decisions: using Bayesian nets and MCDA, Knowledge Based Systems 14 (2001) 307-325. 
[16] C.L. Hwang, K. Yoon, Multiple Attributes Decision Making Methods and Application, Springer-Verlag, Berlin Heidelberg, 1981.

[17] F. Herrera, E. Herrera-Viedma, Linguistic decision analysis: steps for solving decision problems under linguistic information, Fuzzy Sets and Systems 115 (2000) 67-82.

[18] F. Herrera, E. Herrera-Viedma, L. Martinez, A fusion approach for managing multi granularity linguistic term sets in decision making, Fuzzy Sets and Systems 114 (2000) 43-58.

[19] A. Kaufmann, M.M. Gupta, Introduction to Fuzzy Arithmetic: Theory and Applications, Van Nostrand Reinhold, New York, 1985.

[20] G.S. Liang, Fuzzy MCDM based on ideal and anti-ideal concepts, European Journal of Operational Research 112 (1999) 682-691.

[21] C. Liu, M. Wang, Y. Pang, A multiple criteria linguistic decision model (MCLDM) for human decision making, European Journal of Operational Research 76 (1994) 466-485.

[22] A.M. Marmol, J. Puerto, F.R. Fernandez, The use of partial information on weights in multicriteria decision problems, Journal of Multi-criteria Decision Analysis 7 (1998) 322-329.

[23] G.A. Miller, The magic number seven, plus or minus two, Psychological Review 63 (1956) 81-97.

[24] C.C. Robert, R. Fullér, Fuzzy multiple criteria decision making: recent developments, Fuzzy Sets and Systems 78 (1996) 139-153.

[25] R.A. Ribeiro, Fuzzy multiple attribute decision making: A review and new preference elicitation techniques, Fuzzy Sets and Systems 78 (1996) 155-181.

[26] R.M. Tong, P.P. Bonissone, A linguistic approach to decision making with fuzzy sets, IEEE Transactions on Systems Man and Cybernetic Vol. SMC-10 (1980) 716-723.

[27] E. Triantaphyllou, Multi-Criteria Decision Making Methods: A Comparative Study, Kluwer Academic Publishers, Dordrecht/Boston/London, 2000.

[28] P. Vincke, Multicriteria Decision Aid, J Wiley, New York, 1992.

[29] W. Wang, K.L. Poh, Fuzzy MCDM based on confidence analysis, Fuzzy Economic Review VIII (2) (2003) 25-28.

[30] H.F. Wang, Z.H. Huang, Top-down fuzzy decision making with partial preference information, Fuzzy Optimization and Decision Making 1 (2002) 161-176.

[31] W. Watthayu, Y. Peng, A Bayesian network based framework for multicriteria decision making, in MCDM 2004, Whistler, B.C. Canada August 6-11, 2004.

[32] C.H. Yeh, H. Deng, An algorithm for fuzzy multicriteria decision making, Proc. of the IEEE International Conference on Intelligent Processing Systems, 1997, pp. 1564-1568. 
[33] C.H. Yeh, H. Deng, H. Pan, Multi-criteria analysis for dredger dispatching under uncertainty, Journal of the Operational Research Society 50 (1999) 35-43.

[34] C.H. Yeh, H. Deng, Y.H. Chang, Fuzzy multicriteria analysis for performance evaluation of bus companies, European Journal of Operational Research 126 (2000) 459-473.

[35] R.R. Yager, Fuzzy modeling for intelligent decision making under uncertainty, IEEE Transactions on Systems Man and Cybernetics - Part B: Cybernetics 30 (2000) 60-70.

[36] R.R. Yager, On the valuation of alternatives for decision-Making under uncertainty, International Journal of Intelligent Systems, 17 (2002) 687-707.

[37] R.R. Yager, On the evaluation of uncertain courses of action, Fuzzy Optimization and Decision Making 1 (2002) 13-41.

[38] L.A. Zadeh, Fuzzy sets, Information and Control 8 (1965) 338-353.

[39] L.A. Zadeh, The Linguistic Approach and Its Application to Decision Analysis, Proc. of Conference on Directions in Decentralized Control, Many-person Optimization and Large Scale Systems, U.C. Ho and S.M.Kitter (eds.), Plenum Press, 1976, pp. 339-370.

[40] H.J. Zimmermann, Fuzzy Set Theory and Its Applications, Kluwer Academic Publishers, Boston/Dordrecht/London, 2001. 


\section{List of Tables}

Table 1 Decision matrix and weight vector

\begin{tabular}{|c|c|c|c|}
\hline & Price(Pounds; 0.3) & Journey time(Minutes; 0.5) & Comfort([1,10]; 0.2) \\
\hline Car & $(9,10,12)$ & $(70,100,120)$ & $(4,5,6)$ \\
\hline Taxi & $(20,24,25)$ & $(60,70,100)$ & $(7,8,10)$ \\
\hline Train & $(15,15,15)$ & $(70,80,90)$ & $(1,4,7)$ \\
\hline
\end{tabular}

Table 2 Performance matrix

\begin{tabular}{|c|c|c|c|}
\hline & Price(Pounds; 0.3) & Journey time (Minutes; 0.5) & Comfort $([1,10] ; 0.2)$ \\
\hline Car & $(0.520,0.600,0.640)$ & $(0.000,0.167,0.417)$ & $(0.400,0.500,0.600)$ \\
\hline Taxi & $(0.000,0.040,0.200)$ & $(0.167,0.417,0.500)$ & $(0.700,0.800,1.000)$ \\
\hline Train & $(0.400,0.400,0.400)$ & $(0.250,0.333,0.417)$ & $(0.100,0.400,0.700)$ \\
\hline
\end{tabular}

Table 3 Weighted performance matrix

\begin{tabular}{|c|c|c|c|}
\hline & Price(Pounds; 0.3) & Journey time (Minutes; 0.5) & Comfort([1,10]; 0.2) \\
\hline Car & $(0.1560,0.1800,0.1920)$ & $(0.000,0.0835,0.2084)$ & $(0.0800,0.1000,0.1200)$ \\
\hline Taxi & $(0.0000,0.0120,0.0600)$ & $(0.0835,0.2084,0.2500)$ & $(0.1400,0.1600,0.2000)$ \\
\hline Train & $(0.1200,0.1200,0.1200)$ & $(0.1250,0.1665,0.2084)$ & $(0.0200,0.0800,0.1400)$ \\
\hline
\end{tabular}

Table 4 Performance index

\begin{tabular}{|c|c|c|c|c|c|}
\hline \multicolumn{2}{|c|}{ Car } & \multicolumn{2}{c|}{ Taxi } & \multicolumn{2}{c|}{ Train } \\
\hline $\mathrm{P}$ & Order & $\mathrm{P}$ & Order & $\mathrm{P}$ & Order \\
\hline 0.1294 & 1 & 0.1275 & 2 & 0.1248 & 3 \\
\hline
\end{tabular}

Table 5 Linguistic terms of risk attitudes

\begin{tabular}{|l|l|l|}
\hline Linguistic term & $\begin{array}{l}\text { Triangular fuzzy number derived } \\
\text { from }\left(a_{1}, a_{2}, a_{3}\right) \text { for benefit } \\
\text { criteria }\end{array}$ & $\begin{array}{l}\text { Triangular fuzzy number derived } \\
\text { from }\left(a_{1}, a_{2}, a_{3}\right) \text { for cost criteria }\end{array}$ \\
\hline Absolutely optimistic (AO) & $\left(a_{1}, a_{3}, a_{3}\right)$ & $\left(a_{1}, a_{1}, a_{3}\right)$ \\
\hline Very optimistic (VO) & $\left(a_{1},\left(a_{2}+3 a_{3}\right) / 4, a_{3}\right)$ & $\left(a_{1},\left(a_{2}+3 a_{1}\right) / 4, a_{3}\right)$ \\
\hline Optimistic (O) & $\left(a_{1},\left(a_{2}+a_{3}\right) / 2, a_{3}\right)$ & $\left(a_{1},\left(a_{2}+a_{1}\right) / 2, a_{3}\right)$ \\
\hline Fairly optimistic (FO) & $\left(a_{1},\left(3 a_{2}+a_{3}\right) / 4, a_{3}\right)$ & $\left(a_{1},\left(3 a_{2}+a_{1}\right) / 4, a_{3}\right)$ \\
\hline Neutral (N) & $\left(a_{1}, a_{2}, a_{3}\right)$ & $\left(a_{1}, a_{2}, a_{3}\right)$ \\
\hline Fairly pessimistic (FP) & $\left(a_{1},\left(3 a_{2}+a_{1}\right) / 4, a_{3}\right)$ & $\left(a_{1},\left(3 a_{2}+a_{3}\right) / 4, a_{3}\right)$ \\
\hline Pessimistic (P) & $\left(a_{1},\left(a_{2}+a_{1}\right) / 2, a_{3}\right)$ & $\left(a_{1},\left(a_{2}+a_{3}\right) / 2, a_{3}\right)$ \\
\hline Very pessimistic (VP) & $\left(a_{1},\left(a_{2}+3 a_{1}\right) / 4, a_{3}\right)$ & $\left(a_{1},\left(a_{2}+3 a_{3}\right) / 4, a_{3}\right)$ \\
\hline Absolutely pessimistic (AP) & $\left(a_{1}, a_{1}, a_{3}\right)$ & $\left(a_{1}, a_{3}, a_{3}\right)$ \\
\hline
\end{tabular}


Table 6 Performance index with respect to risk attitudes

\begin{tabular}{|l|c|c|c|c|c|c|}
\hline \multirow{2}{*}{} & \multicolumn{2}{|c|}{ Car } & \multicolumn{2}{c|}{ Taxi } & \multicolumn{2}{c|}{ Train } \\
\cline { 2 - 7 } & $\mathrm{P}$ & Order & $\mathrm{P}$ & Order & $\mathrm{P}$ & Order \\
\hline AO & 0.1465 & 1 & 0.1418 & 2 & 0.1363 & 3 \\
\hline VO & 0.1419 & 1 & 0.1380 & 2 & 0.1333 & 3 \\
\hline O & 0.1375 & 1 & 0.1343 & 2 & 0.1303 & 3 \\
\hline FO & 0.1333 & 1 & 0.1308 & 2 & 0.1275 & 3 \\
\hline N & 0.1294 & 1 & 0.1275 & 2 & 0.1248 & 3 \\
\hline FP & 0.1263 & 1 & 0.1233 & 2 & 0.1221 & 3 \\
\hline P & 0.1235 & 1 & 0.1193 & 3 & 0.1196 & 2 \\
\hline VP & 0.1208 & 1 & 0.1154 & 3 & 0.1173 & 2 \\
\hline AP & 0.1183 & 1 & 0.1119 & 3 & 0.1151 & 2 \\
\hline
\end{tabular}

Table 7 Performance index under neutral risk attitude with 11 confidence levels

\begin{tabular}{|c|c|c|c|c|c|c|c|c|c|c|c|}
\hline & \multicolumn{10}{|c|}{ Confidence level } \\
\cline { 2 - 13 } & 0 & 0.1 & 0.2 & 0.3 & 0.4 & 0.5 & 0.6 & 0.7 & 0.8 & 0.9 & 1.0 \\
\hline Car & 0.1294 & 0.1269 & 0.1243 & 0.1217 & 0.1189 & 0.1160 & 0.1131 & 0.1100 & 0.1068 & 0.1035 & 0.1000 \\
\hline Taxi & 0.1275 & 0.1264 & 0.1252 & 0.1240 & 0.1229 & 0.1217 & 0.1206 & 0.1196 & 0.1185 & 0.1176 & 0.1167 \\
\hline Train & 0.1248 & 0.1228 & 0.1208 & 0.1188 & 0.1167 & 0.1146 & 0.1126 & 0.1105 & 0.1084 & 0.1063 & 0.1042 \\
\hline
\end{tabular}

Table 8 Linguistic terms of confidence attitude

\begin{tabular}{|l|l|}
\hline Linguistic term & Membership function \\
\hline Absolutely confident (AC) & $\mu_{A C}(\alpha)=\left\{\begin{array}{cc|}1, \quad \alpha=1 \\
0, & \text { otherwise }\end{array}, \alpha \in[0,1]\right.$. \\
\hline Very confident (VC) & $\mu_{V C}(\alpha)=\left(\mu_{C}(\alpha)\right)^{2}=\alpha^{2}, \alpha \in[0,1]$. \\
\hline Confident (C) & $\mu_{C}(\alpha)=\alpha, \alpha \in[0,1]$. \\
\hline Fairly confident (FC) & $\mu_{F C}(\alpha)=\left(\mu_{C}(\alpha)\right)^{0.5}=\sqrt{\alpha}, \alpha \in[0,1]$. \\
\hline Neutral (N) & $\mu_{U}(\alpha)=1, \alpha \in[0,1]$. \\
\hline Fairly non-confident (FNC) & $\mu_{F N C}(\alpha)=\left(1-\mu_{C}(\alpha)\right)^{0.5}=\sqrt{1-\alpha}, \alpha \in[0,1]$. \\
\hline Non-confident (NC) & $\mu_{N C}(\alpha)=1-\mu_{C}(\alpha)=1-\alpha, \alpha \in[0,1]$. \\
\hline Very non-confident (VNC) & $\mu_{V C}(\alpha)=\left(1-\mu_{C}(\alpha)\right)^{2}=(1-\alpha)^{2}, \alpha \in[0,1]$. \\
\hline & $\mu_{A N C}(\alpha)=\left\{\begin{array}{cc}1, & \alpha=0 \\
0, & \text { otherwise }\end{array}, \alpha \in[0,1]\right.$. \\
\hline Absolutely non-confident(ANC) & \\
\hline
\end{tabular}


Table 9 Performance index under neutral risk attitude with respect to confidence attitudes

\begin{tabular}{|l|c|c|c|c|c|c|}
\hline \multirow{2}{*}{} & \multicolumn{2}{|c|}{ Car } & \multicolumn{2}{c|}{ Taxi } & \multicolumn{2}{c|}{ Train } \\
\cline { 2 - 7 } & $\mathrm{P}$ & Order & $\mathrm{P}$ & Order & $\mathrm{P}$ & Order \\
\hline $\mathrm{AC}$ & 0.1000 & 3 & 0.1167 & 1 & 0.1042 & 2 \\
\hline $\mathrm{VC}$ & 0.1071 & 3 & 0.1189 & 1 & 0.1088 & 2 \\
\hline $\mathrm{C}$ & 0.1085 & 3 & 0.1185 & 1 & 0.1093 & 2 \\
\hline $\mathrm{FC}$ & 0.1110 & 3 & 0.1197 & 1 & 0.1112 & 2 \\
\hline $\mathrm{N}$ & 0.1143 & 2 & 0.1207 & 1 & 0.1134 & 3 \\
\hline FNC & 0.1189 & 2 & 0.1227 & 1 & 0.1167 & 3 \\
\hline NC & 0.1202 & 2 & 0.1228 & 1 & 0.1175 & 3 \\
\hline VNC & 0.1239 & 2 & 0.1252 & 1 & 0.1206 & 3 \\
\hline ANC & 0.1294 & 1 & 0.1275 & 2 & 0.1248 & 3 \\
\hline
\end{tabular}

Table 10 Performance index of Car under risk and confidence attitudes

\begin{tabular}{|l|c|c|c|c|c|c|c|c|c|}
\hline Car & AO & VO & O & FO & N & FP & P & VP & AP \\
\hline AC & 0.0950 & 0.0963 & 0.0976 & 0.0988 & 0.1000 & 0.0976 & 0.0951 & 0.0926 & 0.0901 \\
\hline VC & 0.1101 & 0.1091 & 0.1083 & 0.1076 & 0.1071 & 0.1042 & 0.1014 & 0.0987 & 0.0960 \\
\hline C & 0.1138 & 0.1122 & 0.1108 & 0.1095 & 0.1085 & 0.1056 & 0.1028 & 0.1000 & 0.0973 \\
\hline FC & 0.1179 & 0.1158 & 0.1140 & 0.1124 & 0.1110 & 0.1080 & 0.1051 & 0.1023 & 0.0995 \\
\hline N & 0.1238 & 0.1211 & 0.1186 & 0.1163 & 0.1143 & 0.1113 & 0.1084 & 0.1056 & 0.1029 \\
\hline FNC & 0.1314 & 0.1279 & 0.1246 & 0.1216 & 0.1189 & 0.1157 & 0.1127 & 0.1098 & 0.1071 \\
\hline NC & 0.1338 & 0.1300 & 0.1264 & 0.1231 & 0.1202 & 0.1170 & 0.1140 & 0.1111 & 0.1084 \\
\hline VNC & 0.1389 & 0.1348 & 0.1309 & 0.1272 & 0.1239 & 0.1207 & 0.1177 & 0.1148 & 0.1121 \\
\hline ANC & 0.1465 & 0.1419 & 0.1375 & 0.1333 & 0.1294 & 0.1263 & 0.1235 & 0.1208 & 0.1183 \\
\hline
\end{tabular}

Table 11 Ranking order of $\mathrm{Car}$ under risk and confidence attitudes

\begin{tabular}{|l|c|c|c|c|c|c|c|c|c|}
\hline Car & AO & VO & O & FO & N & FP & P & VP & AP \\
\hline AC & 1 & 2 & 2 & 3 & 3 & 3 & 3 & 3 & 3 \\
\hline VC & 1 & 2 & 2 & 2 & 3 & 3 & 3 & 3 & 3 \\
\hline C & 1 & 1 & 2 & 2 & 3 & 3 & 3 & 3 & 3 \\
\hline FC & 1 & 1 & 2 & 2 & 3 & 3 & 3 & 3 & 2 \\
\hline N & 1 & 1 & 2 & 2 & 2 & 2 & 2 & 1 & 1 \\
\hline FNC & 1 & 1 & 1 & 2 & 2 & 2 & 2 & 1 & 1 \\
\hline NC & 1 & 1 & 1 & 2 & 2 & 2 & 1 & 1 & 1 \\
\hline VNC & 1 & 1 & 1 & 1 & 2 & 1 & 1 & 1 & 1 \\
\hline ANC & 1 & 1 & 1 & 1 & 1 & 1 & 1 & 1 & 1 \\
\hline
\end{tabular}

Table 12 Performance index of Taxi under risk and confidence attitudes

\begin{tabular}{|l|c|c|c|c|c|c|c|c|c|}
\hline Taxi & AO & VO & O & FO & N & FP & P & VP & AP \\
\hline AC & 0.0905 & 0.0989 & 0.1059 & 0.1117 & 0.1167 & 0.1103 & 0.1045 & 0.0993 & 0.0944 \\
\hline VC & 0.1050 & 0.1094 & 0.1131 & 0.1162 & 0.1189 & 0.1129 & 0.1073 & 0.1022 & 0.0973 \\
\hline C & 0.1087 & 0.1119 & 0.1145 & 0.1166 & 0.1185 & 0.1127 & 0.1073 & 0.1023 & 0.0976 \\
\hline FC & 0.1127 & 0.1150 & 0.1169 & 0.1185 & 0.1197 & 0.1141 & 0.1088 & 0.1038 & 0.0992 \\
\hline N & 0.1187 & 0.1195 & 0.1201 & 0.1204 & 0.1207 & 0.1153 & 0.1103 & 0.1055 & 0.1011 \\
\hline FNC & 0.1263 & 0.1255 & 0.1245 & 0.1236 & 0.1227 & 0.1176 & 0.1128 & 0.1082 & 0.1039 \\
\hline NC & 0.1287 & 0.1272 & 0.1257 & 0.1242 & 0.1228 & 0.1179 & 0.1132 & 0.1088 & 0.1046 \\
\hline VNC & 0.1339 & 0.1316 & 0.1293 & 0.1272 & 0.1252 & 0.1204 & 0.1158 & 0.1115 & 0.1074 \\
\hline ANC & 0.1418 & 0.1380 & 0.1343 & 0.1308 & 0.1275 & 0.1233 & 0.1193 & 0.1154 & 0.1119 \\
\hline
\end{tabular}


Table 13 Ranking order of Taxi under risk and confidence attitudes

\begin{tabular}{|l|c|c|c|c|c|c|c|c|c|}
\hline Taxi & AO & VO & O & FO & N & FP & P & VP & AP \\
\hline AC & 2 & 1 & 1 & 1 & 1 & 1 & 1 & 1 & 1 \\
\hline VC & 2 & 1 & 1 & 1 & 1 & 1 & 1 & 1 & 1 \\
\hline C & 2 & 2 & 1 & 1 & 1 & 1 & 1 & 1 & 2 \\
\hline FC & 2 & 2 & 1 & 1 & 1 & 1 & 1 & 1 & 3 \\
\hline N & 2 & 2 & 1 & 1 & 1 & 1 & 1 & 2 & 3 \\
\hline FNC & 2 & 2 & 2 & 1 & 1 & 1 & 1 & 3 & 3 \\
\hline NC & 2 & 2 & 2 & 1 & 1 & 1 & 2 & 3 & 3 \\
\hline VNC & 2 & 2 & 2 & 2 & 1 & 2 & 2 & 3 & 3 \\
\hline ANC & 2 & 2 & 2 & 2 & 2 & 2 & 3 & 3 & 3 \\
\hline
\end{tabular}

Table 14 Performance index of Train under risk and confidence attitudes

\begin{tabular}{|l|c|c|c|c|c|c|c|c|c|}
\hline Train & $\mathrm{AO}$ & $\mathrm{VO}$ & $\mathrm{O}$ & $\mathrm{FO}$ & $\mathrm{N}$ & $\mathrm{FP}$ & $\mathrm{P}$ & $\mathrm{VP}$ & $\mathrm{AP}$ \\
\hline $\mathrm{AC}$ & 0.0717 & 0.0832 & 0.0922 & 0.0991 & 0.1042 & 0.1018 & 0.0989 & 0.0953 & 0.0912 \\
\hline VC & 0.0903 & 0.0968 & 0.1019 & 0.1059 & 0.1088 & 0.1062 & 0.1034 & 0.1002 & 0.0967 \\
\hline $\mathrm{C}$ & 0.0954 & 0.1004 & 0.1043 & 0.1072 & 0.1093 & 0.1068 & 0.1040 & 0.1010 & 0.0977 \\
\hline FC & 0.1002 & 0.1042 & 0.1073 & 0.1096 & 0.1112 & 0.1086 & 0.1059 & 0.1029 & 0.0988 \\
\hline $\mathrm{N}$ & 0.1079 & 0.1102 & 0.1118 & 0.1129 & 0.1134 & 0.1108 & 0.1081 & 0.1053 & 0.1025 \\
\hline FNC & 0.1172 & 0.1175 & 0.1175 & 0.1172 & 0.1167 & 0.1141 & 0.1115 & 0.1088 & 0.1062 \\
\hline NC & 0.1204 & 0.1199 & 0.1193 & 0.1185 & 0.1175 & 0.1149 & 0.1123 & 0.1097 & 0.1072 \\
\hline VNC & 0.1264 & 0.1251 & 0.1236 & 0.1221 & 0.1206 & 0.1179 & 0.1153 & 0.1128 & 0.1104 \\
\hline ANC & 0.1363 & 0.1333 & 0.1303 & 0.1275 & 0.1248 & 0.1221 & 0.1196 & 0.1173 & 0.1151 \\
\hline
\end{tabular}

Table 15 Ranking order of Train under risk and confidence attitudes

\begin{tabular}{|l|c|c|c|c|c|c|c|c|c|}
\hline Train & $\mathrm{AO}$ & $\mathrm{VO}$ & $\mathrm{O}$ & $\mathrm{FO}$ & $\mathrm{N}$ & $\mathrm{FP}$ & $\mathrm{P}$ & $\mathrm{VP}$ & AP \\
\hline $\mathrm{AC}$ & 3 & 3 & 3 & 2 & 2 & 2 & 2 & 2 & 2 \\
\hline VC & 3 & 3 & 3 & 3 & 2 & 2 & 2 & 2 & 2 \\
\hline $\mathrm{C}$ & 3 & 3 & 3 & 3 & 2 & 2 & 2 & 2 & 1 \\
\hline FC & 3 & 3 & 3 & 3 & 2 & 2 & 2 & 2 & 1 \\
\hline $\mathrm{N}$ & 3 & 3 & 3 & 3 & 3 & 3 & 3 & 3 & 2 \\
\hline FNC & 3 & 3 & 3 & 3 & 3 & 3 & 3 & 2 & 2 \\
\hline NC & 3 & 3 & 3 & 3 & 3 & 3 & 3 & 2 & 2 \\
\hline VNC & 3 & 3 & 3 & 3 & 3 & 3 & 3 & 2 & 2 \\
\hline ANC & 3 & 3 & 3 & 3 & 3 & 3 & 2 & 2 & 2 \\
\hline
\end{tabular}




\section{List of Figures}

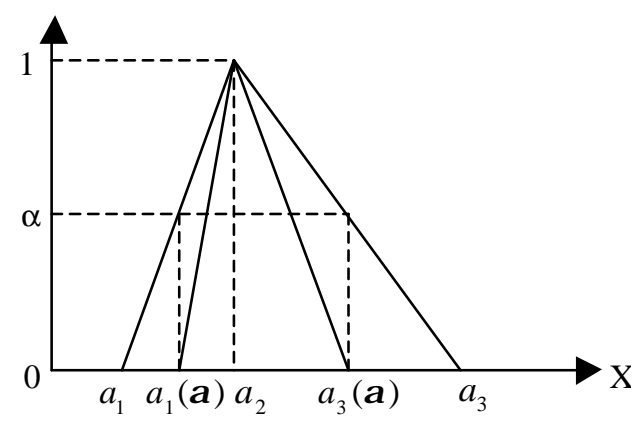

Figure $1 \mathrm{~A}$ triangular fuzzy number $\tilde{A}$ and its $\alpha$-cut triangular fuzzy number 